\title{
Valuations of diversity: The role of marquee quotas in creative industries
}

\author{
Working Paper $^{1}$
}

\author{
Alanna Stuart \\ Independent Scholar \\ Toronto, ON \\ Canada \\ @alannastuart \\ Kim de Laat \\ Mitacs Postdoctoral Research Fellow \\ Department of Sociology, Brock University \\ St. Catharines, ON \\ Canada \\ kdelaat@brocku.ca \\ @kimdelaat
}

\begin{abstract}
We examine how creative industry workers engage with diversity, absent a formal organizational mandate to do so. Through in-depth interviews with independent music industry personnel $(\mathrm{N}=50)$, we find that marquee quotas -- racially diverse representation on rosters and festival bills -- guide how diversity is sought and implemented. Such quotas are justified via four distinct valuations of diversity: aesthetic, economic, reputational, and moral. Both racialized and white participants justify the importance of diversity on moralistic grounds. By contrast, white participants more often justify the value of diversity by making claims about the aesthetic, economic and reputational benefits of marquee quotas. The deployment of these more selfserving valuations has consequences for the extent to which people of colour can be authentically included. Our analysis contributes to critiques of the socio-economic role and consequences of diversity initiatives, within the context of a creative industry.
\end{abstract}

Key words: Diversity; valuation; commodification; moral norms; creative industries

\footnotetext{
${ }^{1}$ Both authors contributed equally. This manuscript received ethics approval from the University of Toronto (RIS Human Protocol No. 36173). We extend our heartfelt thanks to all of the interview participants who took time to speak with us, as well as to our research assistants: Rachael Carson, Marie-Lise Drapeau-Bisson and Leon Liberman. This project received funding from Social Resources for Equity, led by Kayla McGee and Sergio Elmir.
} 
The pursuit of diversity in organizations is fraught with tension. In the best-case scenario, equitable representation is achieved, and this diversity is accompanied by discomfort and interpersonal conflict that ultimately leads to better decision making and, hopefully, a more equitable work environment for underrepresented groups (Phillips 2014). In the worst-case scenario, diversity initiatives represent 'benign variation' or the 'manufacture of cohesion' that are more symbolic platitudes than transformative institutional changes (Mohanty 2003; Noon 2007; Alexander 2005; Ahmed 2012).

Despite the cynicism that pervades both academic and popular understandings of diversity initiatives, their pursuit remains a critical focus of study and an important aspect of organizational life. With few exceptions (e.g., Ely and Thomas 2001), most research on diversity initiatives has focused on its implementation in large, white-collar organizations that have legal or institutional mandates to deliver results (Dobbin and Kalev 2016; Dobbin, Schrage, and Kalev 2015; Hoque and Noon 2004). Such research findings may not be applicable to creative industries, which vary in several ways. Creative industries tend to be small or micro enterprises that lack formal HR departments. Workers are more often hired on a contractual basis and lack the benefits of full-time employment, which may complicate recruitment strategies (Holgate and McKay 2009). Companies in creative fields are more likely to evade basic business principles and engage in nepotism and cronyism (Rossman 2012). And workers rely on informal social networks for job opportunities, which may undermine diversity initiatives (Holgate and McKay 2009; Newkirk 2019). At the same time, creative workers are on average more socially progressive than those working in non-creative sectors (Gill 2014; Lewis and Brooks 2005). In brief, diversity initiatives may look different across creative enterprises. 
Taking these differences as our point of departure, this article examines how those in a creative sector engage with diversity. In an era when racist ideologies and practices persist absent explicit racism (Bonilla-Silva 2006), how (if at all) do those who are predisposed to progressive change go about enacting it, absent a formal mandate to do so? And what are the consequences? Our case study is the Toronto independent music industry. Through in-depth interviews with record label personnel, performing artists, managers, booking agents, and show promoters/festival organizers $(\mathrm{N}=50)$, we find that the use of marquee quotas -- representation of racialized performing artists in prominent, visible domains -- guides how diversity is sought and implemented in this field. We identify two domains in which marquee quotas are used: on festival and concert line-ups, and on managerial, agency, and label rosters. Such quotas are justified by way of four distinct valuations of diversity: aesthetic, economic, reputational, and moral. Because moral valuations are used alongside more self-serving valuations -- the benefits of which accrue to white-dominated organizations -- marquee quotas as a diversity initiative do not alter the "institutional whiteness" of the creative industry in which they operate.

In what follows, we outline patterns in the use of diversity valuations and assess their implications for the commodification of diversity. Our analysis integrates insights from the sociologies of organizations, cultural production, and race/ethnicity. By providing novel empirical data and an understanding of the mechanisms through which diversity is pursued and how it is justified in a creative field, we contribute to critiques of the socio-economic role of diversity initiatives more broadly.

1. The business case for diversity 
The ideal of diversity is lauded in North American society, and most people agree that it is a valuable goal both culturally and organizationally (Bell and Hartmann 2007; Edelman, Riggs Fuller and Mara-Drita 2001). At the same time, how diversity is defined and how diversity initiatives are implemented remain sources of contention and confusion. Part of the issue is that many white people find it hard to talk about racial diversity and articulate why it matters, preferring instead to address the issue in abstract terms, or avoid talking about it altogether (Bell and Hartmann 2007; Eliasoph 1999). This ambiguity and avoidance has implications for organizational contexts, where diversity measures may diverge from legal mandates to increase the number of underrepresented groups (Edelman, Riggs Fuller and Mara-Drita 2001; Hirschman, Berrey and Rose-Greenland 2016), resulting either in initiatives that benefit white women rather than racialized minorities (Kalev, Dobbin and Kelly 2006) or in inadequate results overall (Berrey 2015; Embrick 2011).

As a non-remunerative metric of organizational success, the pursuit of diversity in business contexts has a central place within the circulation of moral economies. Moral economies factor in norms regarding the responsibilities and rights of individuals and institutions with respect to others, apart from or in light of financial transactions (Sayer 2000). Diversity, however, is more than a moral pursuit; since the civil rights movement, companies and corporations have ascribed economic value to diversity by making a business case for it (Berrey 2015; Embrick 2011). Research indicates that organizational diversity along the lines of race and ethnicity (in addition to other lines of difference like gender and age) is not only beneficial for promoting inclusion and equity, but also for generating profit and competitive advantage (Cox and Blake 1991; Herring 2009; Holger 2019). While some contest the extent to which diverse organizational representation spurs competitive advantage (Milliken and Martins 1996; Reagans, 
Zuckerman and McEvily 2004), diversity practitioners nevertheless often justify the pursuit of diversity based on economic values, practices, and metrics (Berrey 2015; Newkirk 2019). When diversity is valued economically in these ways, attention to redressing discrimination and reducing racial inequality is minimized in favour of a model that financializes the value of nonwhite "human capital" (Thomas 2019). In such contexts, the benefits of increasing diversity accrue primarily to organizations rather than individuals. This discrepancy is symptomatic of the challenges stemming from diversity initiatives.

Scholarship documenting the implementation of diversity initiatives demonstrates how difficult it is to accomplish meaningfully (Berrey 2015). Efforts to stamp out bias in hiring decisions via diversity training can, ironically, hamper the hiring of underrepresented groups (Dobbin, Schrage and Kalev 2015), or channel the benefits of such programs to white women over and above people of colour (Kalev, Dobbin and Kelly 2006). A study of undergraduate admissions practices finds that when the drive to increase racial representation on campus relied on a quantifiable point system, this approach was poorly received. Quantifying the representation of non-white applicants represented an oversimplification of racial difference that could be deemed offensive by affirmative action and anti-affirmative action activists alike, and made its implementation more problematic (Hirschman, Berrey and Rose-Greenland 2016). It is precisely because racial constructs are infused with morality that diversity initiatives are difficult to implement in any systematic and beneficial way.

1a. Racism and diversity initiatives in creative industries

The task of fostering diverse representation in creative industries is further complicated; racialized individuals have long been defined by and confined to musical genres in ways that are 
both financially rewarding and stigmatizing (Davis 1999; Dowd 2003; Dowd and Blyler 2002; Lena 2012; Morris 2019; Negus 1999; Roy 2004). Integration into artistic communities is not simply a demographic issue of recruitment or retention. Symbolic boundaries and colorblind racism operate in ways that make entry into certain communities more difficult for people of colour than it might otherwise appear (Berrey 2015; Bonilla-Silva 2006; Erigha 2016; Hall 2006; Li 1994; Saha 2017, 2018).

Historically, there has been a lack of research on the valuation and commodification of race and ethnicity in cultural production, (Hesmondhalgh and Saha 2013; Saha 2018), and inequality in creative industries more broadly (Brook et al. 2021). However, this has changed in recent years, with some attention being paid to diversity initiatives. A study of audio-visual workers (including workers in broadcast radio, animation, television and commercial production, post-production, among others) finds that diversity mandates were not enough to increase job application rates by underrepresented groups (Holgate and McKay 2009). Because of the increasing casualization of employment opportunities, Black and minority ethnic workers preferred to rely on their social networks, which was a relatively more durable mechanism for securing work gigs. The finding echoes other research in creative industries pointing to the importance of social networks -- which are likewise racially constituted -- in securing opportunities in precarious or portfolio careers (de Laat 2015; O’Mahoney and Bechky 2006; Potts et al. 2008). Examining the history of diversity initiatives in the United States, which is more litigious than other national contexts, Newkirk (2019) finds that formal diversity initiatives are not designed to decrease discrimination against underrepresented groups, but merely to discount accusations of intent in courts of law. As elsewhere, diversity initiatives in creative 
industries serve as symbolic gestures to public opinion (Ahmed 2012; Saha 2018; Edelman et al. 2001). ${ }^{2}$

Other creative industries scholarship focuses on valuations of race. For example, racebased judgements about the economic worth of a given film or actor can influence export distribution strategies, whereby majority-Black films are held back by expectations of failure (Erigha 2018, 2019, 2020). In fiction publishing, cultural intermediaries are given autonomy in decision-making, such that their preference for stories and authors that approximate their own socio-cultural background goes unchecked, leading to an underrepresentation of non-white authors more broadly (Childress and Nault 2019).

An important subset of these conversations pertains to the role of typecasting in creative industries. Typecasting occurs when creative personnel are assigned to simple, focused identities based on pre-existing cultural stereotypes (Zuckerman et al. 2003). Recent analyses find that stereotypical identities are even more restricted for people of colour (Yuen 2016). For example, the thematic content of pop songs performed by Black women are patterned in such a way that lyrical themes remain in dialogue with harmful stereotypes about "jezebels" and "welfare queens" (Collins 2004; de Laat 2019). The process of typecasting is also somatic and includes judgments about the extent to which ascriptive markers of differences are inscribed into a performer's skillset (Friedman and O'Brien 2017; Hamann and Beljean 2021). Typecasting both constrains modes of representation while providing opportunities for underrepresented groups,

\footnotetext{
${ }^{2}$ Contra the predominant findings diversity initiatives serving merely as symbolic gestures, at least one experiment finds that exposure to even a single diversity initiative -- announcing a racialized replacement for the role of Captain America -- can lead to changes in attitudes regarding diversity initiative more broadly, with audiences becoming more receptive to the practice (Gubitz and Avant 2020).
} 
insofar as it increases chances of success in unpredictable creative industries when one "fits" the predetermined mold. Notwithstanding potential career benefits associated with typecasting, its practice highlights instances of "segregated visibility" of underrepresented groups (Hall 2006; Saha 2017). Because success is achieved through reproducing tokenistic cultural stereotypes, inequality is likewise reproduced.

The operation of marquee quotas found in Toronto's independent music industry builds on our understanding of the role played by segregated visibility. In line with this research, marquee quotas likewise render diverse representation visible, but in such a way that the overrepresentation of whiteness in the independent music industry is not disrupted (Hall 1996; Saha 2017; Ray 2019). To understand valuations of informal diversity initiatives in the independent music industry, we analyze the discourse and actions of indie music personnel with regard to increasing diverse representation. What do diversity initiatives look like in the context of a creative field, where efforts to increase diverse representation are largely uncoordinated? And how do people make sense of it?

\section{Data, methods, and research site}

We use the independent music industry in Toronto, Canada as our case study. Studying diversity in creative fields is analytically important for two main reasons. First, the relationship between race and musical innovation is complicated and deeply rooted. Integrating diverse representation into creative fields is not merely an issue of financial consideration, and this research site enables us to examine the circulation of competing logics of valuation (Antal et al. 2015; Banks 2006; Boltanski and Thevenot 1999, 2006). Second, some companies in creative sectors (e.g. record labels and management firms) may be oriented towards restricted production where one of the 
prevalent rewards is symbolic capital (Bourdieu 1993). In such environments, innovation thrives because there is less pressure to produce art that will be widely received and consumed. Because people in creative sectors value forms of capital in addition to economic capital, the practices and decision-making undergirding engagement with diversity may differ than what is found in other industries, making it both a unique and important site for studying the interplay of economic and non-economic valuations of diversity.

While there are no data specific to the music industry indicating rates of employment, people of colour are underrepresented in the Canadian arts and entertainment sectors more broadly (Hill Strategies 2019). Despite the lack of statistical data on rates of representation, many have remarked upon the whiteness of independent music in Canada, and highlighted its lack of inclusivity (Bottineau 2020; Sheikh 2016). Commentators note that the independent music industry (in Toronto, as elsewhere) is overwhelmingly white (Hesmondhalgh 1999; James-Wilson 2020; Kabango 2016; Sahim 2015), despite operating in a city where 51 percent of the population identifies as a person of colour. Critics debate the reason for such racial/ethnic insularity, however one account attributes it to the growing importance of authenticity demanded by genre forbearers punk and hip-hop, which discourages the cross-pollination of genres (and which also happen to be patterned along lines of race/ethnicity) (Wilson 2007). The dearth of performers and racialized music in Toronto has motivated panels on the topic of racism in independent music (Gillis 2016), as well as the creation of advocacy groups leading to calls for action (Bottineau 2020). As such, diversity and systemic racism were prevalent topics for industry personnel as we began this study.

The data consist of in-depth, semi-structured interviews conducted by a team of four interviewers. We interviewed people in a variety of different roles -- agents (N=9), artists 
$(\mathrm{N}=12)$, label personnel $(\mathrm{N}=13)$, managers $(\mathrm{N}=11)$ and promoters $(\mathrm{N}=5)$-- to discern differences and similarities in mindsets across the indie music industry. Table 1 provides a description of participants' occupational roles. Non-white women and men and white women are overrepresented in our sample compared to their actual numbers in the music industry, to highlight their experiences.

[Table 1 here]

We interviewed those who are part of the indie music industry "establishment" (i.e., those with high public profiles) by building a recruitment list based on two sources: the Canadian Independent Music Association (CIMA) membership database, and the Polaris Prize long list. The CIMA website lists contact information for all its indie record label members. Using the CIMA database of record labels as our point of departure, we randomly selected a representative number of labels, musicians/bands signed to labels based in Toronto, as well as the managers and agents of musicians/bands. Because not all indie record labels are members of CIMA, we also consulted the long list nominees for the Polaris Music Prize, a prestigious music award conferred by a select panel of music critics without regard to musical genre or commercial popularity. We used the same sampling strategy for the Polaris list as we did for the CIMA list. As there is no representative way to develop a list of show promoters, we used our personal knowledge of the independent music community in Toronto to recruit people in this role. Our recruitment strategy generated a list of 69 individuals in a variety of roles. Fifty individuals elected to participate in our study.

[Table 2 here]

The sample consists of 35 white and 15 non-white participants. While we asked participants to be specific in how they self-identify along lines of race and ethnicity, we use the aggregate 
categories of white and non-white to protect the confidentiality of interview participants that might otherwise be easily identified. Two of the interviewers are white, and two of the interviewers identify as people of colour. Given the mixed findings regarding racial/ethnic dynamics in interview settings (Twine and Warren 2000), we initially paired interviewers with participants based on interviewers' availability. However, halfway through the interview process we made a concerted effort to pair people of color together as a measure of self-care for the interviewers, who reported having to perform additional emotional labour of maintaining neutral reactions to some comments by white respondents. Non-white interviewers conducted all but two of the interviews with non-white participants.

Interviews were conducted in person and over the phone and lasted on average 1.5 hours. The interview guide included questions about strategies used when deciding to represent or book a performing artist, personal definitions of and experiences with diversity, the social organization of participants' workplaces, as well as demographic questions regarding the participants' race/ethnicity, gender, education level, and salary. Performing artists were additionally asked about their experiences with labels, management, agents, and promoters. Following each interview, detailed research notes were written up (approximately 500-1000 words each) and after each interviewer conducted five interviews, a team meeting was held to discuss preliminary themes. We then each wrote a longer, more detailed research memo elaborating on initial findings and patterns in the data. Once interviews were completed, another research assistant coded the interview transcripts in Dedoose. The research assistant and authors each coded the same four interviews to ensure agreement about coding categories and pertinent themes. Most of the categories emerging at this initial stage were based on the interview guide and preliminary insights from the research memos. However, we also allowed for the emergence of new themes 
throughout the coding process, at which point the research assistant iteratively returned to the coded interviews to add new codes (Emerson, Fretz, and Shaw 2011).

Once interviews revealed the importance of representation on label, management and agency rosters, and on festival bills, we conducted a count analysis of the representation of Indigenous, Black, and other racialized artists on two festival line-ups and two record label rosters over time. We selected two of the largest independent music festivals that happen annually in the greater Toronto area and conducted an annual search for the festival line-ups, relying on Way Back Machine (archive.org) to access older iterations of rosters. We selected two of the largest independent record labels for which there were yearly snapshots available in the archive. We coded every other year of the label rosters, and every year of festival lineups for which we could find information. The date range used for assessing changes in representation of BIPOC artists over time extends from 2006 to 2020. Race and ethnicity were identified through using publicly available online data (i.e., artist biographies in which race/ethnicity or Indigeneity is mentioned). Absent any media where artists self-identify, we examined images of artists online and binary-coded for whether they appear white-passing. This is a crude measure that may not reflect people's actual racial/ethnic identity (Dixon and Telles 2017). We use it nonetheless because if, as our participants suggest, race/ethnicity is being used as a selection criterion for inclusion on festival line-ups or artist rosters, decision-makers may likewise be basing their perceptions on a similar measure of white-passing.

\section{Findings: Engaging with Diversity}

\subsection{The role of marquee quotas}

Our interviews with performing artists and independent music industry personnel revealed the importance of two areas where diversity, via the representation of visible minorities, is sought: 
(1) management, band, agency and label rosters, and (2) festival and concert line-ups. In each of these domains, increased representation of diverse artists is encouraged through informal (i.e., not formally mandated) quotas. Because such forms of representation are highly visible ways of achieving diversity (in contrast to actively recruiting people of colour into 'behind the scenes' organizational roles and positions of power), we refer to this phenomenon as marquee quotas.

Since the decline of album sales, live performance has become the main source of revenue for the music industry (Hall 2020; Stahl and Meier 2012). According to the artists we interviewed, live performance opportunities are important for providing access to different audiences and potential career support. Most artists interviewed identified music festival performances as the tipping point that launched their career, which positions festivals as an influential force within the independent music scene (Paleo and Wijnberg 2006).

Interviewees stated that festival and concert promoters are increasingly candid about their desire for diverse representation. According to Caleb (agent, white, 30s), this demand from festivals has an impact on the booking process, influencing which artists are considered for lineups:

We definitely have had that conversation on the phone where festivals are saying, 'I need more of this.' That happens often ... there's no question that there's some festivals that are like, you know, 'Too many white men.' And so therefore I've got to switch, in mid-pitch, to go, 'okay, well interesting enough, here's the more ethnic side of the roster,' or the leaning more to this gender side of the roster.

The managers and record label personnel we interviewed, as well as some of the musicians, likewise describe trying to strike a balance in terms of diverse representation on their rosters and in their bands, respectively. Some describe explicitly pursuing diverse representation, whereas 
for others, working with racially diverse artists was something that they were cognizant of, but it wasn't the main factor motivating their decision-making.

To ground our participants' insights on the role of marquee quotas, we counted the representational rates of Black, Indigenous, and people of colour (BIPOC) performing artists on two record label rosters, and two annual music festivals, all located in Toronto. Figures 1-4 display the proportion of performing artists who are not white passing across time.

[Figures 1-4 about here].

Apart from Record Label 'A,' which has more varied rates of representation year over year, there is an increase in the number of racialized artists over time on the roster and festival lineups in our sample, particularly since 2018. Collectively, this substantiates our participants' observation that representation of racialized artists on rosters and line-ups has increased.

\subsection{Valuations of diversity}

In lieu of HR personnel to manage and assess the impact of diversity initiatives, marquee quotas are used as benchmarks for how well organizations and groups are faring in fostering diverse representation in the independent music industry. When asked their opinions on the pursuit of marquee quotas, or diversity more generally, participants referred to four ways of valuating diversity: aesthetic, economic, reputational, and moral. As we argue below, the self-serving reasons for pursuing marquee quotas underscore how diversity itself may be commodified and sought by the predominantly white record industry personnel.

[Table 3 here]

Table 3 outlines the frequency of valuations based on manager, agent, promoter, and label personnel racial/ethnic identity. Aesthetic, economic, and reputational valuations of 
diversity initiatives were most commonly used by white participants. Moral valuations were frequently deployed by both white and non-white participants. ${ }^{3}$ Performing artists not included in Table 3, however in the analysis that follows, we include their perceptions of the valuations used to assess marquee quotas.

\subsubsection{Aesthetic valuation}

White respondents often remarked that diverse representation on festival bills was important because, otherwise, things are boring. For instance, when asked why diversity is important, Tess (record label worker, white, 40s) says, "I think it matters because it keeps it interesting. It's not boring. Even like the Justin Bieber song that got huge that was with that Spanish guy. I don't even remember ... Despacito! There you go.” The implication is that the value of including artists of colour is derived from the novelty they bring. Similarly, when Zachary (musician, white, 30s) was asked about how his white band decided to hire Black back-up singers, he replies:

I think there was an effort to want to be more diverse than just the five of us, I don't know. Obviously, there would've been some great white soul singers that could do the trick too, but to me, it's just a more interesting look and more representative look.

In addition to assessing the singers' talent, Zachary's comment suggests that the visual aesthetics of having Black singers on stage was something that factored into his band's decision-making. For Sebastian (musician, white, 30s), the aesthetic value of novelty is inextricably tied to one's identity as a racialized person:

I'll look at four white dudes on stage and say, yep, I know that story 'cuz it's probably in the ballpark of mine. I feel like rock n' roll used to have a mystique about it, you know? And so much of it is recycled now. Like when Allan Lomax went down and did those field recordings,

\footnotetext{
${ }^{3}$ The use of valuations may overlap, and participants often spoke about diversity using more than one type of valuation over the course of their interview.
} 
there were blues singers ... that shit's insane ... I mean, there needs to be some sort of resurgence of some of that truth has never been heard before.

Interviewer: You think that racialized artists are more likely to be providing that music?

Sebastian: Yeah, because I certainly don't think it's gonna be another fucking white guy.

Sebastian's example of Allan Lomax, the renowned folklorist who painstakingly recorded and catalogued blues music by African Americans in the southern United States, often by problematic means (Miller 2010), suggests that the value of including people of colour is derived from the "mystique" they offer.

When asked whether conversations about diversity happen when he's pitching artists to festivals, Malcolm (booking agent, white, 30s) shares:

I do pitch the diversity of my clients to festivals.

Interviewer: Can you give me an example of how that gets articulated?

Malcolm: It's just part of my pitch. So I'll -- for example, I have a new RnB group. They're two gay sisters from Newfoundland via Madagascar. I basically -- what I just told you would be a line in the pitch. I think it's exciting to have something different. Right out of the gate, just hearing that is appealing. You probably were like oh, shit, I'd love to hear that because it's fucking cool, and they're amazing. That's better than five-piece alt rock band from Hamilton. It's just not - it's just a sales tactic to try to get people excited about it, so you use -- the diversity part is the pitch.

While used as a sales tactic, Malcolm is making an aesthetic claim for the importance of diversity; the music is innovative and worthy of inclusion because of the performers' unique identities. In this case, the act he represents is interesting in part because they're queer, Black immigrants.

In response to being asked for his thoughts on the push for diverse representation on festival bills, Bob (concert promoter, white, 50s) responds: 
I'm laughing at any promoter that it worries because me, I'm diverse enough. I don't have to worry about it. Nobody will ever come to me and say, 'hey, you gotta diversify. Hey, you need a quota.' I say, 'Yeah, my quotas were already filled a long time ago.' And they'll continue to be. Just natural. You know? 'Cause I will look out for it and I will pay a little extra attention to a Black indie rock act. It's something different. You get bored with sameness. You wanna see different stuff, you know? You wanna hear new things.

For Bob, diversity is likewise equated with innovation; it matters because it keeps things interesting and novel.

Performing artists of colour felt differently about their racial/ethnic identity being valuated in aesthetic terms. Aria (musician, non-white, 30s) when recounting her manager's expertise with the Asian music market, shared:

[My manager] is awesome at that market. He knows that market really well. As a weird aside, he was adamant that I keep Jones in my performing name. I was like, 'why is that? I want to be Aria, that's it. Bjork -- Aria -- that's my jam, right!' I was very proud of my [first] name. But he was like, 'keep the last name in there.'

Interviewer: Did he explain why?

Aria: He said because it's a white name, and the Asian market will eat it up more because 'yeah, you're a Westerner and a mixed girl.' I was like, 'that's fucked up', but, you know, I was young and impressionable. I actually didn't really want the Jones because I just thought it was kind of a weird thing. And I know there was a famous Jones already existing in California somewhere, so I wanted to separate myself from that artist. And again, aesthetically, I just liked the way Aria looked. But anyhow I went for the full hard jam and yeah, that's that.

In this instance, Aria's heritage is being used instrumentally as a marketing feature, in light of her manager's belief that her mixed-race identity makes her more appealing to an Asian market.

Thinking of performing artists of colour as progenitors of novelty is not entirely inaccurate; throughout the $20^{\text {th }}$ century, Black musicians and artists in particular have been responsible for the most important musical innovations, including blues, jazz, hip hop, dancehall, and punk. While the stereotype of people of colour as purveyors of innovation and mystique can 
be beneficial if it means they gain representation on festival and concert bills, it is also the case that the stereotypical link between race/ethnicity and novelty is problematic because it perpetuates the "otherness" and racial distancing of non-white individuals (Leung 2016; Said 1979). In addition, rendering racial/ethnic identity as commensurate to innovation erases the work that people of colour put into their art, and the agency they have over their successes (Zanoni, Thoelen, and Ybema 2017).

\subsubsection{Economic valuation}

Though quotas for record labels, agencies, and festivals are not formally mandated, it is the case that government funding of the arts in Canada allocates grant money specifically for underrepresented groups. ${ }^{4}$ This creates an economic incentive to work with racialized artists. Several white industry workers were forthcoming about identifying this economic value of diversity and recognizing their ability to earn additional revenue via granting systems.

For example, Charles (manager, white, 30s) chooses to represent certain Indigenous and racialized artists to improve his chances of receiving government grants. When deciding to work with one artist, he mentions that he was motivated in part because the artist had infrastructure in place, referring to the grant funding they accrued prior to being signed:

We raised $\$ 100,000$ in grants. And then there's that thing that happens in the Indigenous community, or sometimes when you work with diversity artists is that you can weaponize diversity and take advantage of the tokenism. Sometimes you get $3 \mathrm{G}$ 's to do a show. You're the

\footnotetext{
${ }^{4}$ For example, the funding body Ontario Creates includes the following text in their application guide: "Ontario Creates values and supports diversity and gender parity within creative industries. The evaluation criteria for this program includes a bonus score for activities that support and reflect diversity and gender parity in Ontario, and/or applications from Francophone, Indigenous, culturally and otherwise diverse applicants." (Ontario Creates 2020).
} 
only one who's able to do that show. You do it, because that's your niche, identity, whatever, thing. That gives you economic leverage."

Access to grants turned what Charles described as a niche artist into a more viable client.

He encourages his racialized artists to weaponize diversity to take advantage of tokenism and increase the chances for successful grant applications and concert bookings. As a manager, Charles takes a percentage of the revenue his artists bring in; as such, weaponizing diversity is to his benefit in addition to the artist.

Unlike the other valuations of diversity and marquee quotas, economic valuations were used to defend the prioritization of white artists on line-ups and rosters. Darren (agent, white, 50s) relayed his opinions about a conversation he had with a concert promoter:

We run into this thing where diversity is reflected in the festivals we book, right? So, you know, I just had a conversation about it this morning with someone. They were very candid with me saying, 'Well, we need more women, or we need more people of colour.' I struggle with that, I have to admit ... when it comes to festivals and when we're programming that kind of stuff, it frustrates me ... Is it fair to put the pressure and attack the festival promoters? If they feel like there wasn't a better musician that checked those boxes, and therefore, why should I step down in the level of musicianship to check that box? We'll be out of business, potentially.

Like many white people opposed to preferential recruitment and hiring, implicit in Darren's line of reasoning is the belief that merit is not commensurate with the pursuit of diversity (Bobo 1998; Philips 1991; Wilson 2006). Darren thus struggles with aligning his views on the moral importance of diverse representation with economic considerations. Similarly, when Liam (manager, white, 40s) is asked whether he ever considered the diversity of festival bills, he responds:

It came up as an issue last festival season ... the short of it is, should a festival be diverse? No. A festival's primary concern is diversity of music, not diversity of race, diversity of political beliefs. You wanna have a festival whose programming sells tickets. That's hard enough of a thing to do without trying to fill a bunch of affirmative action boxes. 
Leveraging economic valuations of diversity cuts both ways; whereas some seek to justify diverse representation as a means of generating revenue, others use economic valuations to argue against any consideration of racial diversity. In each case, it is white participants that relied on economic reasoning when assessing or disputing the role of diversity in the music business.

\subsubsection{Reputational valuation}

Industry personnel cited reputational concerns as a motivating factor in the pursuit of marquee quotas. These participants believed that boasting a diverse roster would reflect well on them, both to audiences and others within the industry. Hanna (label manager, non-white, 30s) described a new artist her label is working with:

I think we are taking on a new artist who is not established. She's a development artist and she's like, 'I tick all the boxes that people are looking for,' meaning she's a female person of color. She's obviously talented and we wouldn't be working with her otherwise, but I think that maybe factored into wanting to work with her.

Hanna's comment indicates that the pursuit of diversity is so ubiquitous, that this racialized artist jokes about the cachet that working with her confers. Hanna is then asked what she thinks motivates such a comment by the artist, to which she replies:

There has been a bit of chatter about parity on festivals ... And we've [Hanna and her colleagues] always talked about another artist that we have in a band because she identifies as queer and she is a person of colour, and she is Francophone and [laughter] female, so she literally checks all of those boxes if there are boxes to check. But yeah, we're like, 'we can't ever lose her or our entire roster is white basically.' So, yeah, I think it's something that people are thinking about.

Hanna's comment suggests that there are reputational losses to contend with for failing to achieve racial diversity. Similarly, when asked about her experiences with diversity, Carrie (label manager, white, 30s) shares, "I need to look at the breadth of my roster in a diversity sense as 
opposed to just the genre and musical taste sense. I think everyone [in the industry] is now being like, 'Oh, this is -- I mean -- it's my problem and someone will point it out if it's not -- if it's not right." Carrie is articulating a fear over being called out, and the reputational harm it could cost her label.

The racialized artists to whom we spoke perceived the costs of such reputational valuations of diversity differently. Langston (musician, non-white, 30s) shared that:

On the other end of things where I'm getting booked for events - I'm not stupid. I see that, over time, some of these festivals and stuff are trying to be more visibly diverse looking so they can get points from the community and it isn't a really organic thing. It went from last year everybody on the entire festival was white and a man. And now, this year, it's definitely prioritizing women and people of colour and it's like it's because what they think they need to. It didn't feel authentic. You know?

Langston feels tokenized as an artist and as a person of colour when efforts to diversify line-ups do not come from a place of authentic interest in his music, but instead are motivated by optics and publicity.

\subsubsection{Moral valuation}

The fourth and most common way of valuating diversity was to provide moral justifications; both white and racialized participants argued that diversity matters because everyone deserves to have a voice and have that voice heard. Jon (agent, non-white, 30s) is one of only a handful of racialized booking agents in Canada. Reflecting on his time as a festival promoter, he says,

When I was booking festivals and all that stuff, like I had a very diverse line-up. In all my shows I try to include a little bit of everything even when I may have been told no by certain people. Because it's always been important to me, and myself on the business side, I'm like one of the only agents of colour in Canada right now. 
In Jon's case, he does not justify the value of pursuing diverse representation beyond stating that diversity is important to him. And Mark (manager, non-white, 40s), when asked whether he works alongside any people of colour in his management company shares:

I've had a couple [racialized staff]. Actually, it's probably about even, 50/50. But to me, this is where it comes down to, like I don't go out purposely looking for people of colour. I go out purposely looking for somebody who can do the job ... but I probably do prick my eyes and my ears when somebody steps up to the plate and says, hey, I'm interested. Do you know what I mean? I'm like, oh, great. Let me bring you in, let me be a mentor.

Unlike white participants leveraging economic valuations to counter the active recruitment of visible minorities and pitting an understanding of recruiting for diversity as antithetical to meritocratic recruitment, for Mark these pursuits are complementary.

White participants also justified the value of diversity on moral grounds. In so doing, they often expressed concern about tokenizing racialized artists in their pursuit of marquee quotas. Alexandra (agent, white, 30s) deliberates on whether diversity should be explicitly sought:

It's shitty, but I think sometimes, there has to be [an explicit effort]. I don't know. You have these moments where you actually, you know, like the Indigenous category. We see it a lot with Indigenous performing artists; they are asked to be a part of this thing to check that box and to be the token, and you have to maybe try to assess it on a case-by-case sort of basis. I think yes, we do have to do things with intention to try to spark change, but I guess it just has to come down to what does it feel like to the person involved in that?

In expressing her concern over avoiding tokenism, Alexandra conveys that the feelings of the artist involved should be paramount. Brandon (label manager, white, 40s) reflects on his label's approach to signing artists in a similar manner:

We certainly try not to [draw attention to artists' racial/ethnic identity] overtly. Obviously, if someone comes from a Cree background and that is core to their identity and the way that they talk about their music, we are going to add that in their bio. But it's not going to be positioned as, you know, 'Well, if you care about the plight of Indigenous Canadians, you should listen to this music.' That all of a sudden becomes really gross and cynical ... I do feel like there are really great things happening in terms of a general awareness within industries towards trying to 
amplify more diverse voices, but with that amplification, there needs to be a more nuanced approach, which I suppose would be the next step to that would be more diversity within the gatekeepers, the people that are at the label, the people that run the marketing departments.

In speaking of the need for a nuanced approach to achieving diversity, Brandon is reinforcing his own moralistic perspective that diverse representation needs to be genuine and occur across the field of cultural production with gatekeepers too.

\subsection{The role of gatekeepers}

In this study, we have grouped different occupational roles together to develop a broad understanding of workers' perceptions of marquee quotas across the field of the independent music industry. There is a rich literature on the role of cultural intermediaries, and how some creative roles have the power to confer value and legitimacy on creative people and products more than others (Maguire and Matthews 2012). Among the roles included in our sample, agents and promoters, who play a decisive role in helping festivals and concerts meet their quotas by determining who gets booked, are perceived to have gatekeeping authority over performing artists' careers (e.g., Hirsch 2000).

The agents and promoters we spoke to did not harbor self-serving valuations (i.e., economic, aesthetic and reputational) more than those occupying other industry roles. But as this is an interview-based study, we cannot rule out a selection effect where those predisposed to thinking about racial inequality opt in, while others do not. It is possible that outside of our sample, gatekeepers such as agents and promoters are more likely to espouse economic valuations of marquee quotas. This may be attributed to their higher exposure to economic pressures; unlike management companies and record labels that earn money from the sale of 
albums and merchandise, agents and promoters' earnings are derived solely from live performances. The risk and uncertainty involved in their work is thus more concentrated.

Sarah, (agent, white, 30s) remarked about her role that "when you're in a festival buying situation, you have to consider what is going to sell tickets and what's going to sell beer, right?" In general, booking agents and promoters were referenced by others as obstacles to promoting diversity authentically, and perceived to be less committed to individual artists' best interests (unlike managers or label personnel). Rather, for Langston, their commitment is to "put artists into a box":

Sometimes, I'll work with booking agents and they don't give a fuck about you. It's all about the bottom line and the numbers that they have at the end of the year and it's like they work with these giant rock bands that play huge-ass venues. So, they try to put you in the same box as some rock band from Halifax or something, even though it's not the same kind of music and it's not the same audience.

Agents' and promoters' lack of commitment was perceived as problematic because it implied that they were more concerned with following trends, and thus more likely to stop representing artists if their sound fell out of favour with audiences, or more likely to try and book racialized artists for self-serving purposes.

\subsection{Marquee quotas as surface-level engagement}

Often, musical genres align with symbolic boundaries, creating feelings of in-group identity and enabling marginalized groups to self-express in ways that defy denigrating stereotypes (Collins 2004; Perry 2004). Within the independent music industry in Toronto, which is composed largely of labels that fall under the generic category of "indie rock," this is not the case. Indie performing artists are primarily middle class, and its majority-white constituents have not been subject to racial discrimination in ways that motivate them to seek out community membership 
and cultural expression as a means of overcoming racial discrimination and racism. Race as a marker of authenticity is not deployed the same way it is in other genre communities, such as blues (Grazian 2005) and hip hop (Campbell 2014). This is not to deny that white personnel in the independent music industry evaluate colleagues' fit on the basis of race or ethnicity. Several racialized participants shared stories where their presence at a rock venue was questioned. For Cristobal (non-white, 40s, label manager) this meant getting mistaken as a barback, "If I'm talking to someone in a band at a show and then I just kind of introduce myself to someone, chatting with them, they think that I work there, I'm a bar back, rather than I'm there for the show." And Mark (non-white, 40s, manager) shared the story of showing up to his artist's rock show he represented, and another industry person greeted him with "What are you doing here?" as though he didn't belong in the room.

From a relational perspective, the latter instances make the underrepresentation of people of colour an ethical issue. In this respect, it is promising that indie music industry personnel valuate marquee quotas on moral grounds as often as they do. Generally speaking, accommodating diversity through marquee quotas is perceived by most, particularly those using moralistic valuations, to be a necessary but not sufficient effort that can result in surface-level engagement with diversity. Many of the white and non-white individuals we spoke to referred to such quotas as tokenistic, or box ticking. As forms of representation, they can be more beneficial to those who succeed in ticking the boxes -- often white record label personnel and promoters -than the groups they are meant to serve (Ray 2019; Saha 2018). At the same time, our interview participants believe that marquee quotas have an integral role within the music industry economy. 
Interview participants highlighted that while the strategy of marquee quotas has been successful at increasing the representation of racialized workers at the artist level, they have not been implemented to increase racial diversity amongst decision-making positions. Failure to foster diversity within labels, agencies, and other positions of influence limits the effectiveness of marquee quotas in positively impacting the experiences of racialized workers in the industry, and moving from diversity to inclusion (Herring and Henderson 2012; Ray 2019).

Participants describe the makeup of the industry as "whitewashed," and several interviewees referred to the dominant culture as being comprised of "old white guys." This organizational misalignment results in a lopsided industry that sees an increase of diverse artists relying on organizations that may lack the necessary social and cultural understanding to develop their careers. Rachel (manager, white, 30s) points out that:

When you apply for a grant you can check you know, women or Indigenous or disability, but if these people aren't supported on the other side, then it won't help. The grants won't have the same impact if systems in the industry don't support the execution of the projects. ... I've worked with an artist when I was at [X] record label and I just saw the label fumble it. 'Cause, you know, she's a woman and Muslim and North African, and they don't know how to market that. It doesn't fit the 'white man channel' so you need someone to help you market that and reach a wider public. Because music and art is meaningful, but it's also a lot about PR and likes. And as an artist you'll pay your PR so much more money. Yes the recording is expensive, but what will happen is artists get a 30-thousand-dollar grant, record the album but then they can't go on tour because they don't have anyone to book shows. It's a holistic thing really.

Rachel's comment illustrates a shortcoming with deploying marquee quotas unevenly across organizational contexts. Attempts to achieve diverse representation may be overridden when met with cultural biases and misunderstandings (Embrick 2011; Thomas 2017). Mark relays a similar sentiment when he talks about how he warned a friend to be wary of signing to a predominantly white management company that specializes in rock n' roll: 
A friend of mine, a female soul $R \& B$ artist, is being poached right now by a major rock management company, all female-driven -- which is cool -- but there's nobody in that company that knows her fucking genre of music ... This artist right now that I'm talking about, the female artist, I said, "hey, these people are very, very, very connected, very well respected, know the business infrastructure, have all the means to take you to where you need to, but they don't have anybody in-house that reflects who you are, who we are, our culture, our understanding of the music."

While opportunities for artists of colour have improved, racialized interview participants felt that they must often work alongside white industry workers that are ill-equipped to give them the support they need. Through marquee quotas, difference based on race is implicitly neutralized in favour of the perception of fair representation (Hirschman et al. 2016). Yet, discrepancies in the lived experience of artists and industry personnel of colour remain, and the emphasis placed on marquee quotas prevents deeper engagement with diversity and inclusion. The causes and effects of racial inequality in the indie music industry we studied reside within individuals, and pervade organizational routines and resources (Bonilla Silva 1997; Ray 2019). As an outcrop of socioeconomic valuations of diversity, marquee quotas facilitate the commodification of diversity, with the benefits mainly going to labels, managers, and agents in a predominantly white industry. 4. Conclusion

This article examines how racial diversity is pursued and conceptualized by individuals working in a creative industry. We find that industry personnel engage with diversity by attempting to gain diverse representation on festival and concert lineups, and on management and label rosters. Such efforts are not accompanied by the pursuit of diverse representation within firms. This partial pursuit of diversity -- what we refer to as marquee quotas -- is valuated as worthy by means of aesthetic, economic and reputational justifications primarily by white respondents. The salience of moral valuations by white and non-white respondents alike 
indicates that those with socially progressive predispositions may informally pursue diversity initiatives for selfless reasons. However, the simultaneous deployment of more self-serving valuations (aesthetic, and especially reputational and economic) suggests that certain people are less able to control the circulation of valuations, which has consequences for the extent to which they can feel authentically included in organizational contexts (Sayer 2000). More cynically, the circulation of moral valuations of marquee quotas may in some instances align more closely to the idea of "inequality talk," where the rhetorical commitment to diversity replaces more impactful interventions of inter-organizational change and may operate as a means for upholding pre-existing exclusionary boundaries (Brook et al. 2021).

In the context of creative industries that value forms of capital in addition to the financial kind, the importance attributed to marquee quotas means they become part of 'the game' -- the informal rules that govern fields of cultural production and influence social standing (Bourdieu 1993). Racialized artists benefit from funding that is earmarked specifically for them, however many of the benefits accrued from weaponizing diversity also go to predominantly white management companies and record labels that sign racialized artists. Marquee quotas confer authenticity and cultural capital on the cultural intermediaries responsible for their creation. Through their expressions of aesthetic valuations, white music industry personnel signal that performing artists of colour make their rosters and festival line-ups "cool," and "different." And through their expressions of reputational valuations, white industry personnel suggest that marquee quotas help them avoid being called out, allowing their social standing to remain intact. The marquee quota approach to diversity initiatives raises questions about whether solutions can be addressed by surface-level representation rather than through exposing the "assumptions, 
micro-practices, social relations, and power dynamics that define our collective cultural common sense about the nature of social difference and the practices of inequality." (Gray 2016:246).

Our research findings highlight the interplay of racialized valuations within moral economies, something that has heretofore received little attention from economic sociologists. Data are at the individual-level, however research participants are drawing from their experiences as members of small organizations that collectively comprise the independent music industry. The patterning of individually held valuations along lines of racial identity suggests that they contribute to the broader racialization of the indie music industry. As such we believe that the findings exemplify the tenet that racialized organizations can limit the efficacy of personal agency (Ray 2019); while moral valuations drive most respondents' beliefs in the value of diversity, they circulate alongside other valuations that may be too self-serving to motivate the kinds of transformative organizational change necessary to move from diversity to inclusion, notwithstanding efforts to the contrary.

\section{References}

Ahmed, S. (2012). On being included: Racism and diversity in institutional life. Duke University Press.

Alexander, M. J. (2005). Pedagogies of Crossing: Meditations on Feminism. Sexual Politics.

Antal, A. B., Hutter, M., \& Stark, D. (Eds.). (2015). Moments of valuation: Exploring sites of dissonance. Oxford University Press, USA.

Banks, M. (2006). Moral economy and cultural work. Sociology, 40(3), 455-472.

Bell, J. M., \& Hartmann, D. (2007). Diversity in everyday discourse: The cultural ambiguities and consequences of "happy talk". American Sociological Review, 72(6), 895-914. 
Berrey, E. (2015). The Enigma of Diversity: The Language of Race and the Limits of Racial Justice. University of Chicago Press.

Bobo, L. (1998). "Race, Interests, and Beliefs About Affirmative Action: Unanswered Questions and New Directions." American Behavioral Scientist 41(7):985-1003.

Bonilla-Silva, E. (1997). Rethinking racism: Toward a structural interpretation. American sociological review, 465-480.

Bonilla-Silva, E. (2006). Racism without Racists: Color-Blind Racism and the Persistence of Racial Inequality in the United States. Rowman \& Littlefield Publishers.

Boltanski, L., and Thévenot, L. (1999). The sociology of critical capacity. European journal of social theory, 2(3), 359-377.

Boltanski, L., and Thévenot, L. (2006). On justification: Economies of worth (Vol. 27).

Princeton University Press.

Bottineau, J. 2020. “This Weekly Panel Is Tackling Anti-Black Racism in Canada's Music Industry." Complex Magazine https://www.complex.com/music/2020/08/this-weeklypanel-is-tackling-anti-black-racism-in-canadas-music-industry

Bourdieu, P. (1993). The Field of Cultural Production: Essays on Art and Literature. Columbia University Press.

Brook, O., O'Brien, D., \& Taylor, M. (2021). Inequality talk: How discourses by senior men reinforce exclusions from creative occupations. European Journal of Cultural Studies, 24(2), 498-513.

Campbell, M. V. (2014). The Politics of Making Home: Opening Up the Work of Richard Iton in Canadian Hip Hop Context. Souls, 16(3-4), 269-282.

Childress, C., \& Nault, J. F. (2019). Encultured biases: The role of products in pathways to inequality. American Sociological Review, 84(1), 115-141.

Collins, P. H. (2004). Black sexual politics: African Americans, gender, and the new racism. Routledge.

Communications MDR. 2016. Environmental Scan of the Culture Sector. Province of Ontario e Ministry of Tourism, Culture and Sport .

Cox, T. H., and Blake, S. (1991). Managing cultural diversity: Implications for organizational competitiveness. Academy of Management Perspectives, 5(3), 45-56.

Creative Industries Federation. n.d. "Industry Statistics Creative Industries Federation." Retrieved January 23, 2020 (https://www.creativeindustriesfederation.com/statistics). 
Davis, A. 1999. Blues Legacies and Black Feminism: Gertrude "Ma" Rainey, Bessie Smith, and Billie Holiday. New York: Vintage.

de Laat, K. (2015). "Write a Word, Get a Third" Managing Conflict and Rewards in Professional Songwriting Teams. Work and Occupations, 42(2), 225-256.

de Laat, K. (2019). Singing the romance: Gendered and racialized representations of love and postfeminism in popular music. Poetics, 77, 101382

Dixon, A. R., and Telles, E. E. (2017). Skin color and colorism: Global research, concepts, and measurement. Annual Review of Sociology, 43, 405-424.

Dobbin, F, Kim, S and Kalev, A. (2011). "You Can't Always Get What You Need: Organizational Determinants of Diversity Programs." American Sociological Review 76(3): 386-411.

Dobbin, F. and Kalev, A. (2016). "Why Diversity Programs Fail." Harvard Business Review, July 1.

Dobbin, F., Schrage, D., and Kalev, A. (2015). "Rage against the Iron Cage: The Varied Effects of Bureaucratic Personnel Reforms on Diversity." American Sociological Review 80(5):1014-44.

Dowd, T. (2003). "Structural Power and the Construction of Markets: The Case of Rhythm and Blues." Pp. 147-201 in Comparative Social Research. Vol. 21. Bingley: Emerald.

Dowd, T. and Blyler, M. (2002). "Charting Race: The Success of Black Performers in the Mainstream Recording Market, 1940 to 1990.” 24.

Edelman, L. B., Fuller, S. R., and Mara-Drita, I. (2001). Diversity rhetoric and the managerialization of law. American Journal of Sociology, 106(6), 1589-1641.

Eliasoph, N. (1999). "Everyday racism" in a culture of political avoidance: Civil society, speech, and taboo. Social Problems, 46(4), 479-502.

Ely, R. and Thomas, D. (2001). "Cultural Diversity at Work: The Effects of Diversity Perspectives on Work Group Processes and Outcomes." Administrative Science Quarterly 46(2):229-73.

Embrick, D. (2011). The diversity ideology in the business world: A new oppression for a new age. Critical sociology, 37(5), 541-556.

Emerson, R., Fretz, R. and Shaw, L. (2011). Writing Ethnographic Fieldnotes, Second Edition. University of Chicago Press. 
Erigha, M. (2016). Do African Americans direct science fiction or blockbuster franchise movies? Race, genre, and contemporary Hollywood. Journal of Black Studies, 47(6), 550-569.

Erigha, M. (2020). "Racial Valuation: Cultural Gatekeepers, Race, Risk, and Institutional Expectations of Success and Failure." Social Problems.

Erigha, M. (2018). "On the Margins: Black Directors and the Persistence of Racial Inequality in Hollywood." Ethnic and Racial Studies

Erigha, M. (2019). The Hollywood Jim Crow: The racial politics of the movie industry. NYU Press.

European Commission. n.d. Diversity for Talent and Competitiveness: The SME Business Case for Diversity. Retrieved from http://www.iegd.org/pdf/Task\%202\%20-\%20SMEs.pd

Friedman, S., \& O’Brien, D. (2017). Resistance and resignation: Responses to typecasting in British acting. Cultural Sociology, 11(3), 359-376.

Gill, R. (2014). Unspeakable inequalities: Post feminism, entrepreneurial subjectivity, and the repudiation of sexism among cultural workers. Social Politics: International Studies in Gender, State \& Society, 21(4), 509-528.

Gillis, C. (2016). Real talk about racism in the Toronto music scene. Now Magazine: https://nowtoronto.com/real-talk-about-racism-in-the-toronto-music-scene

Gray, H. (2016). 18. Precarious Diversity: Representation and Demography. In Precarious creativity (pp. 241-253). University of California Press.

Grazian, D. (2005). Blue Chicago: The search for authenticity in urban blues clubs. University of Chicago Press.

Gubitz, S. R., \& Avant, D. (2020). Racializing Captain America: How Racial Attitudes Affect Perceptions of Affirmative Action and Diversity Initiatives in Media. Journalism \& Mass Communication Quarterly, 97(3), 683-703.

Hamann, J., \& Beljean, S. (2021). Career gatekeeping in cultural fields. American Journal of Cultural Sociology, 9(1), 43-69.

Hall, S. (2006). What is this 'black 'in black popular culture? (pp. 479-489). Routledge.

Hall, S. (2020). "This is how COVID-19 is affecting the music industry." World Economic Forum.

Hesmondhalgh, D., \& Saha, A. (2013). Race, ethnicity, and cultural production. Popular Communication, 11(3), 179-195. 
Herring, C. (2009). Does diversity pay?: Race, gender, and the business case for diversity. American Sociological Review, 74(2), 208-224.

Herring, C. and Henderson, L. (2012). "From Affirmative Action to Diversity: Toward a Critical Diversity Perspective.” Critical Sociology 38(5):629-43.

Hill Strategies. (2019). A Statistical Profile of Artists in Canada in 2016. https://hillstrategies.com/resource/ statistical-profile-of-artists-in-canada-in-2016/.

Hirsch, P. M. (2000). Cultural industries revisited. Organization science, 11(3), 356-361.

Hirschman, D., Berrey, E., and Rose-Greenland, F. (2016). Dequantifying diversity: affirmative action and admissions at the University of Michigan. Theory and Society, 45(3), 265-301.

Holgate, J., \& McKay, S. (2009). Equal opportunities policies: how effective are they in increasing diversity in the audio-visual industries' freelance labour market?. Media, Culture \& Society, 31(1), 151-163.

Holger, D. (2019). "The Business Case for More Diversity." Wall Street Journal https://www.wsj.com/articles/the-business-case-for-more-diversity-11572091200

Hoque, K., \& Noon, M. (2004). Equal opportunities policy and practice in Britain: evaluating the 'empty shell' hypothesis. Work, employment and society, 18(3), 481-506.

James-Wilson, M. (2020). What It's Like to Be Black in Indie Music. Pitchfork Magazine: https://pitchfork.com/features/article/what-its-like-to-be-black-in-indie-music/

Kabango, S. (Jan.28, 2016). 3 artists call out racism in Toronto's music scene. Q. CBC Radio: https://www.cbc.ca/radio/q/schedule-for-thursday-january-28-2016-1.3423368/3-artistscall-out-racism-in-toronto-s-music-scene-1.3423383

Kalev, A., Dobbin, F. and Kelly, E. (2006). "Best Practices or Best Guesses? Assessing the Efficacy of Corporate Affirmative Action and Diversity Policies." American Sociological Review 71(4): 589-617.

Lena, J. (2012). Banding Together: How Communities Create Genres in Popular Music. Princeton University Press.

Leung, L. (2016). The creative other: Marginalization of and from the creative industries. The Journal of Arts Management, Law, and Society, 46(4), 200-211.

Lewis, G. and Brooks, A. (2005). “A Question of Morality: Artists' Values and Public Funding for the Arts." Public Administration Review 65(1):8-17. 
Li, P. S. (1994). A world apart: The multicultural world of visible minorities and the art world of Canada. Canadian Review of Sociology/Revue canadienne de sociologie, 31(4), 365-391.

Maguire, J. S., \& Matthews, J. (2012). Are we all cultural intermediaries now? An introduction to cultural intermediaries in context.

Malik, S. (2013). "Creative diversity": UK public service broadcasting after multiculturalism. Popular Communication, 11(3), 227-241.

Ministry of Tourism, Culture and Sport and Communications MDR. 2016. Environmental Scan of the Culture Sector in Ontario. https://www.ontario.ca/document/environmental-scanculture-sector-ontario-culture-strategy-background-document/sector-profile-culturalindustries

Miller, K. (2010). Segregating Sound: Inventing Folk and Pop Music in the Age of Jim Crow. Durham NC: Duke University Press Books.

Milliken, F. J., and Martins, L. L. (1996). Searching for common threads: Understanding the multiple effects of diversity in organizational groups. Academy of management review, 21(2), 402-433.

Mohanty, C. T. (2003). "Under western eyes" revisited: Feminist solidarity through anticapitalist struggles. Signs: Journal of Women in culture and Society, 28(2), 499-535.

Morris, W. (2019). "Why Is Everyone Always Stealing Black Music?” The New York Times, August 14.

Mueller, J. (2017). "Producing Colorblindness: Everyday Mechanisms of White Ignorance." Social Problems 64:219-38.

Negus, K. (1999). Music Genres and Corporate Cultures. Psychology Press.

Newkirk, P. (2019). Diversity, Inc: The Failed Promise of a Billion-dollar Business. Bold Type Books.

Noon, M. (2007). The fatal flaws of diversity and the business case for ethnic minorities. Work, employment and society, 21(4), 773-784.

O'Brien, D., Laurison, D., Miles, A., \& Friedman, S. (2016). Are the creative industries meritocratic? An analysis of the 2014 British Labour Force Survey. Cultural Trends, 25(2), 116-131.

O'Brien, D., \& Oakley, K. (2015). Cultural value and inequality: A critical literature review. Arts and humanities research council. 
O'Mahony, S., \& Bechky, B. A. (2006). Stretchwork: Managing the career progression paradox in external labor markets. Academy of Management Journal, 49(5), 918-941.

Paleo, I., and Wijnberg, N. (2006). "Classification of Popular Music Festivals: A Typology of Festivals and an Inquiry into Their Role in the Construction of Music Genres." International Journal of Arts Management 8(2):50-61.

Perry, I. (2004). Prophets of the hood: Politics and poetics in hip hop. Duke University Press.

Philips, M. (1991). "Preferential Hiring and the Question of Competence." Journal of Business Ethics 10(2):161-63.

Phillips, K. W. (2014). How diversity makes us smarter. Scientific American, 311(4), 43-47.

Potts, J., Cunningham, S., Hartley, J., \& Ormerod, P. (2008). Social network markets: a new definition of the creative industries. Journal of cultural economics, 32(3), 167-185.

Ray, V. (2019). “A Theory of Racialized Organizations.” American Sociological Review 84(1):26-53.

Reagans, R., Zuckerman, E., \& McEvily, B. (2004). How to make the team: Social networks vs. demography as criteria for designing effective teams. Administrative science quarterly, 49(1), 101-133.

Roy, W. (2004). "Race records" and "hillbilly music": institutional origins of racial categories in the American commercial recording industry. Poetics, 32(3-4), 265-279.

Saha, A. (2017). The politics of race in cultural distribution: Addressing inequalities in British Asian theatre. Cultural Sociology, 11(3), 302-317.

Saha, A. (2018). Race and the cultural industries. John Wiley \& Sons.

Sahim, S. (2015). The unbearable Whiteness of indie. Pitchfork.

Said, E. (1979). Orientalism. 1 edition. New York: Vintage.

Sayer, A. (2000). Moral economy and political economy. Studies in political economy, 61(1), 79103.

Sheikh, I. (2016). The politics of music: Why the Canadian music scene lacks diversity. TVO.org: https://www.tvo.org/article/the-politics-of-music-why-the-canadian-musicscene-lacks-diversity 
Stahl, M., and Meier, L. (2012). The firm foundation of organizational flexibility: The 360 contract in the digitalizing music industry. Canadian Journal of Communication, 37(3), 441.

Thomas, J.M. (2017). "Diversity Regimes and Racial Inequality: A Case Study of Diversity University:" Social Currents.

Thomas, J. M. (2019). The Economization of Diversity. Sociology of Race and Ethnicity, 5(4), 471-485.

Twine, F.W., and Warren, J. eds. (2000). Racing Research, Researching Race: Methodological Dilemmas in Critical Race Studies. New York: NYU Press.

Wilson, C. 2007. “The Trouble With Indie Rock." Slate Magazine. https://slate.com/culture/2007/10/the-trouble-with-indie-rock.html

Wilson, T.C. (2006). "Whites' Opposition to Affirmative Action: Rejection of Group-Based Preferences as Well as Rejection of Blacks.” Social Forces 85(1):111-20.

Zanoni, P., Thoelen, A., and Ybema, S. (2017). "Unveiling the Subject behind Diversity: Exploring the Micro-Politics of Representation in Ethnic Minority Creatives' Identity Work." Organization 24(3):330-54.

Zuckerman, E. W., Kim, T. Y., Ukanwa, K., \& Von Rittmann, J. (2003). Robust identities or nonentities? Typecasting in the feature-film labor market. American journal of sociology, 108(5), 1018-1074. 
Table 1. Overview of participants' occupational roles

\begin{tabular}{|c|c|c|c|}
\hline Role & $\mathrm{N}$ & Workplace & Description of role \\
\hline Artist & 12 & N/A & $\begin{array}{l}\text { Singers/musicians are musical artists; they may have a booking agent, manager, record label deal, and/or } \\
\text { publishing deal, or they may perform these duties for themselves. Artists make money through performing live, } \\
\text { selling albums/downloads, and streaming, via royalty payments, music licensing, publishing and commissioning, } \\
\text { and through selling merchandise. They may receive an advance payment from a record label to make an album and } \\
\text { create promotional material, which they are in turn responsible for paying back. Many indie artists also have day- } \\
\text { jobs to make ends meet. }\end{array}$ \\
\hline $\begin{array}{l}\text { Booking } \\
\text { Agent }\end{array}$ & 9 & Agency & $\begin{array}{l}\text { Responsible for finding performance opportunities for artists; usually works alongside other agents, each of whom } \\
\text { represent their own roster of artists. They are often approached by promoters who are interested in booking one of } \\
\text { the artists on their roster. Agents earn revenue by taking a percentage of money paid to artists for each live } \\
\text { performance that they book, usually } 10 \text { percent. Agency size can vary from } 20-50 \text { staff members. }\end{array}$ \\
\hline $\begin{array}{l}\text { Label } \\
\text { personnel }\end{array}$ & 13 & Record label & $\begin{array}{l}\text { Responsible for marketing the artists' musical releases, and handling artist and repertoire (A\&R) duties, including } \\
\text { (but not limited to) organizing the production of music, artwork, and videos. At smaller indie labels, one person } \\
\text { may be responsible for both marketing and A\&R. Some labels are also management companies. Labels earn } \\
\text { revenue through the sale of albums/downloads and streaming, via royalty payments. Indie music label size can vary } \\
\text { from 3-50 staff members. }\end{array}$ \\
\hline Manager & 11 & $\begin{array}{l}\text { Management } \\
\text { company }\end{array}$ & $\begin{array}{l}\text { Responsible for managing the day-to-day affairs for the artist, including fielding performance requests, booking } \\
\text { travel, organizing merchandise, applying for grants, project managing tours and album production, negotiating } \\
\text { contracts, and liaising with the artist's label, agent, as well as show promoters. Managers may work independently } \\
\text { with their own support staff, or they may be part of a larger management company. Some management companies } \\
\text { are also record labels. Managers earn revenue by taking } 10-20 \text { percent of artists' earned revenue. Indie } \\
\text { management companies can vary in size from 1-30 staff members. }\end{array}$ \\
\hline
\end{tabular}




\begin{tabular}{|l|l|l|l|}
\hline Promoter & 5 & $\begin{array}{l}\text { Promotion } \\
\text { company or } \\
\text { self-employed }\end{array}$ & $\begin{array}{l}\text { Responsible for booking artists to play at venues and curating festival lineups; they usually approach artists' agents } \\
\text { or managers to pitch performance opportunities. They may work independently or alongside other promoters, and } \\
\text { are responsible for overseeing concert logistics, setting ticket prices, negotiating performance contracts, and } \\
\text { promoting and marketing the concert/festival. Promoters earn revenue by taking a percentage of a given concert's } \\
\text { profit, usually between 5-20 percent. Promotion company size can vary from 1-50 staff members. }\end{array}$ \\
\hline
\end{tabular}


Table 2. List of interview participants by race/ethnicity and gender

\begin{tabular}{|l|l|l|l|l|}
\hline & Men & Women & Non-binary & Total \\
\hline White participants & 22 & 12 & 1 & 35 \\
\hline Non-white participants & 8 & 7 & 0 & 15 \\
\hline Total & 30 & 19 & 1 & 50 \\
\hline
\end{tabular}

Table 3. Use of diversity valuations by participant race/ethnicity*

\begin{tabular}{|l|r|r|}
\hline & \multicolumn{2}{|r|}{$\begin{array}{r}\text { Frequency of use by research participant } \\
\text { race/ethnicity }\end{array}$} \\
\hline Valuation: & White & Non-white \\
\hline Aesthetic & $9(27 \%)$ & $0(0 \%)$ \\
\hline Economic & $9(27 \%)$ & $1(13 \%)$ \\
\hline Reputational & $2(6 \%)$ & $1(13 \%)$ \\
\hline Moral & $13(40 \%)$ & $6(75 \%)$ \\
\hline Total: & 33 & 8 \\
\hline
\end{tabular}

*Valuations used by managers, agents, promoters, and label personnel. Performing artists are excluded. 


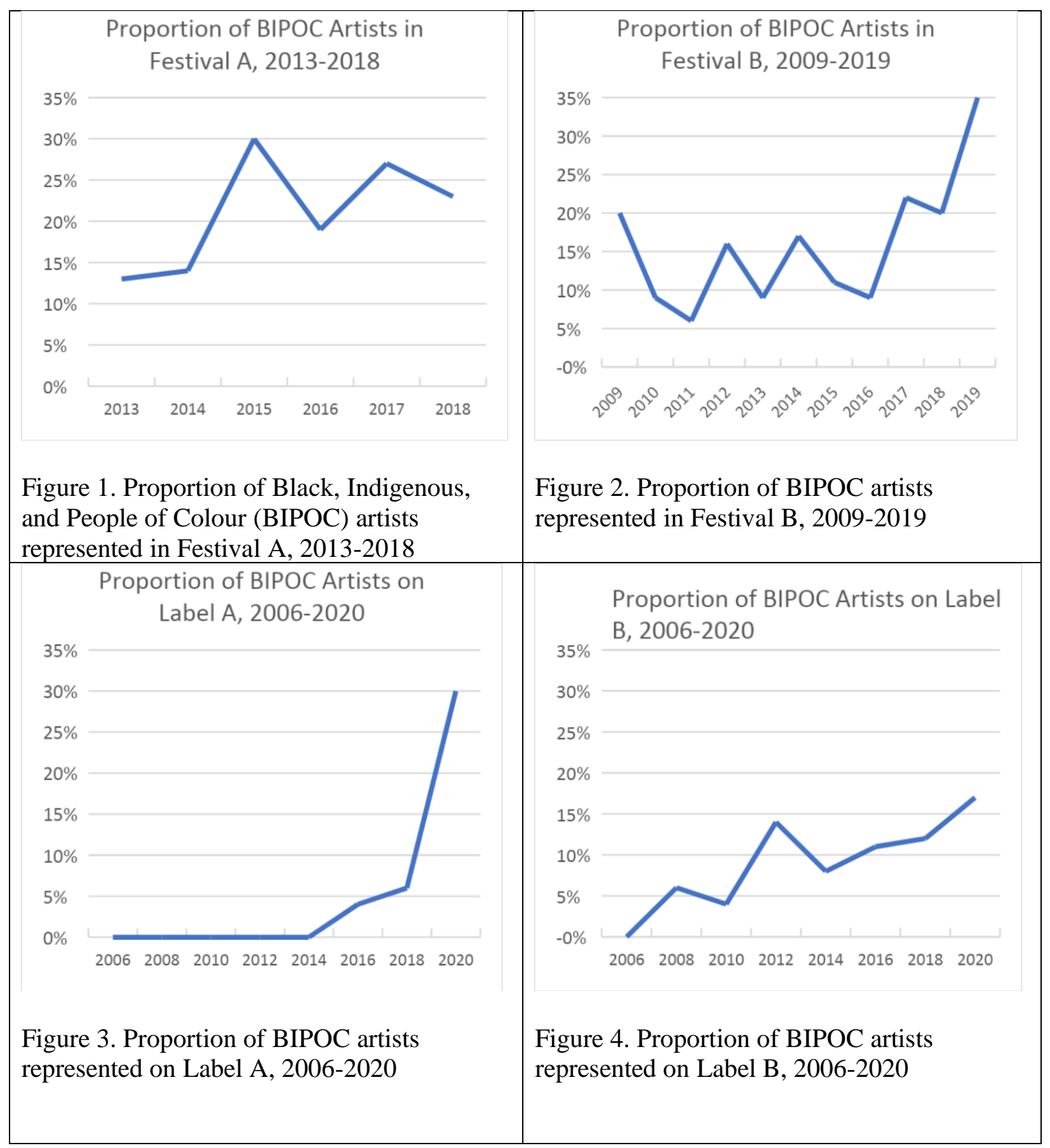

